\title{
Molecular Testing in Thyroid Cancer
}

\author{
An Expert Interview with Hossein Gharib
}

Mayo Clinic, Rochester, MN, US

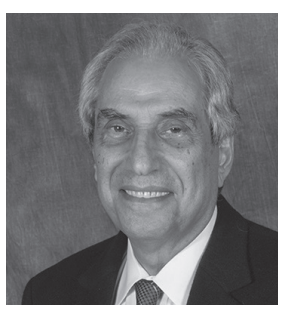

\begin{abstract}
Hossein Gharib
Hossein Gharib received his MD degree from the University of Michigan Medical School and completed his internal medicine residency and fellowship in endocrinology and metabolism at the Mayo Clinic in Rochester, MN. He joined the Mayo Clinic staff in 1972 and was promoted to the rank of Professor of Medicine in 1994. An international authority on thyroid disorders, Dr Gharib has published more than 200 papers and three textbooks, the latest, Thyroid Nodule, published in 2017. He has traveled widely and lectured at more than 350 national and international endocrine events. He has received many honors \& awards, including from the American Thyroid Association (ATA), the Endocrine Society, the American Association of Clinical Endocrinologists (AACE), and the American College of Physicians. He has been an editorial board member of several journals including the Journal of Clinical Endocrinology and Metabolism, Thyroid, Endocrine Practice, Acta Endocrinologica (Buc), and US Endocrinology. He is a past president of the AACE, the American College of Endocrinology, and the ATA.
\end{abstract}

\section{Keywords}

Thyroid cancer, molecular testing, ultrasound-guided fine needle aspiration, RET mutation, BRAF mutation

Disclosure: Hossein Gharib has nothing to disclose in relation to this article.

Acknowledgments: Medical writing assistance was provided by Katrina Mountfort at Touch Medical Media.

Review Process: This is an expert interview and as such, has not undergone the journal's standard peer review process.

Authorship: All named authors meet the criteria of the International Committee of Medical Journal Editors for authorship for this manuscript, take responsibility for the integrity of the work as a whole and have given final approval for the version to be published

open Access: This article is published under the Creative commons Attribution Noncommercial License, which permits any non-commercial use, distribution, adaptation and reproduction provided the original author(s) and source are given appropriate credit. (C) The Authors 2018

Received: April 9, 2018

Published Online: April 27, 2018

Citation: US Endocrinology, 2018;14(1):22-23

Corresponding Author: Hossein Gharib, Mayo Clinic College of Medicine, 200 First St. SW Rochester, MN 55905, US. E: gharib.hossein@mayo.edu

Support: No external funding was received in the publication of this article. t has been estimated that two-thirds of the world population have thyroid nodules, ${ }_{1}^{1}$ and their incidence increases with age. ${ }^{2}$ While most are benign, ${ }^{1}$ the incidence of thyroid cancer has increased

substantially worldwide over the last four decades. ${ }^{3}$ Therefore, there is a need for reliable methods of thyroid nodule evaluation. Fine-needle biopsy with cytologic evaluation remains the standard diagnostic test to distinguish benign from malignant thyroid nodules but has a number of limitations, including its inability to identify aggressive tumors. ${ }^{4}$ In an expert interview, Dr Hossein Gharib of the Mayo Clinic College of Medicine, Rochester, MN, discusses the need for molecular testing in thyroid cancer.

\section{Q. Why is molecular testing for thyroid cancer important?}

Assessment of risk of malignancy (ROM) in thyroid nodules is key to improved care. To assess ROM, we use medical history, physical examination, the results of ultrasound (US)-guided fine needle aspiration biopsy (FNA), and now we have molecular testing. Molecular testing can be diagnostic when used for thyroid nodules or prognostic in thyroid cancer.

For diagnostic use, several molecular tests are now available to separate benign from malignant nodules when FNA cytology is indeterminate. These tests are used by clinicians to avoid surgery when FNA is "suspicious," i.e., neither benign nor malignant.

\section{Q. What are the limitations of currently available tests?}

The main limitation is that the tests are not widely available, particularly worldwide. Their cost is relatively high, especially outside the US. In addition, their positive predictive value is low, which means that when the test is positive, many nodules may not be malignant.

\section{Q. How may these tests help in surgical decision-making in the future?}

BRAFV600, a gene mutation in papillary thyroid cancer (PTC), is a marker of more aggressive tumor behavior. Thus, BRAF-positive tumors are more likely to metastasize to regional lymph nodes or have higher recurrence rates. The strongest argument against the use of BRAF mutation in surgical decision-making in practice is their high prevalence (30-80\%) in PTC. However, it is expected that with more experience, molecular testing-including BRAF-will help us stratify our approach to thyroid cancer. For example, BRAF-positive tumors may require complete thyroidectomy and node dissection.

\section{Q. How may molecular tests help determine prognosis?}

A good example is the RET gene mutation in medullary thyroid carcinoma (MTC). When RET mutation is identified in the proband, family screening is relatively easy: those with a negative RET test are not 
at risk and need no further testing. Furthermore, it is recognized that some subtypes of RET mutations are associated with more aggressive tumors and when present, require more immediate and more aggressive surgery.

\section{Q. What new tests are in advanced development?}

Several tests are becoming available. The RET mutation in MTC is a wellestablished and useful test. The use of BRAF screening needs more evidence before it can be used in routine clinical applications. Testing for the RAS mutation is most common in follicular cancers. The presence of a BRAF mutation coexisting with TERT promoter mutations has been associated with a more aggressive clinical course, but this is not yet in routine use.

In addition, molecular targeted therapy is currently being studied for differentiated thyroid cancers. $\square$

1. Welker MJ, Orlov D. Thyroid nodules. Am Fam Physician. 2003;67:559-66.

2. Dean DS, Gharib H. Epidemiology of thyroid nodules. Best Pract Res Clin Endocrinol Metab 2008:22:901-11.

3. Lim H, Devesa SS, Sosa JA, et al. Trends in Thyroid Cancer Incidence and Mortality in the United States, 1974-2013. JAMA. 2017:317:1338-48.

4. Finley DJ, Zhu B, Barden CB, et al. Discrimination of benign and malignant thyroid nodules by molecular profiling . Ann Surg. 2004;240:425-36; discussion 36-7. 